\title{
El texto descriptivo para fortalecer la competencia comunicativa del español como lengua extranjera
}

\author{
Andrea Lorena Aponte-Buitrago*
}

Magíster en Lingüística, Universidad Pedagógica y Tecnológica de Colombia (UPTC). Licenciada en Idiomas Modernos Español-Inglés. Joven investigadora UPTC 2013, 2014 y 2015, del grupo ELEX. Profesora catedrática de la Escuela de Idiomas de la UPTC, Tunja, Colombia. Correo electrónico:

andrea.aponte@uptc.edu.co

Recibido: 10 de mayo del 2015

Aprobado: 26 de julio del 2015

Cómo citar este artículo: Aponte-Buitrago, Andrea Lorena. "El texto descriptivo para fortalecer la competencia comunicativa del español como lengua extranjera". Rastros Rostros 17.31 (2015): 11-22. Impreso. doi: http://dx.doi.org/10.16925/ra.v17i31.1270

\section{Resumen}

Introducción: este artículo de investigación es producto del proyecto desarrollado como joven investigadora de la Universidad Pedagógica y Tecnológica de Colombia (UPTC), y pertenece al grupo de investigación ELEX de la Escuela de Idiomas. Su propósito fue diseñar, aplicar y analizar diez talleres con la intención de fortalecer la competencia comunicativa de los aprendientes de español como lengua extranjera (ELE), a través del texto descriptivo. Posteriormente, con base en el análisis de la información se diseñó una cartilla. Metodología: se eligió como metodología la investigación-acción. El enfoque fue mixto, ya que incluyó tanto el cualitativo como el cuantitativo. Para la aplicación y análisis de los resultados y posterior publicación de la cartilla, se contó con la participación de cuatro extranjeros aprendientes de ELE que visitan la UPTC. Resultados: Los textos descriptivos sirvieron como estrategia y herramienta para fortalecer la competencia comunicativa de ELE y el afianzamiento de las habilidades en la interpretación, la argumentación, la proposición y el análisis, así como el aprendizaje de nuevo léxico. Conclusión: por medio de esta investigación se comprobó que los estudiantes de ELE expresan de manera objetiva y subjetiva sus ideales, creencias e historias. Asimismo, la propuesta pedagógica se enfocó en actividades, ejercicios y talleres lúdicos en los que fueron capaces de leer, analizar, criticar y comprender de forma eficaz y agradable diferentes tipos de textos descriptivos. A partir de la aplicación de los talleres y el análisis de los mismos, se diseñó la cartilla con el fin de fortalecer la competencia comunicativa de los estudiantes extranjeros.

Palabras clave: competencia comunicativa, ELE (español como lengua extranjera), enseñanza de ELE, texto descriptivo. 


\title{
The Descriptive Text to Strengthen the Communicative Competence of Spanish as a Foreign Language
}

\begin{abstract}
Introduction: this research article is the result of a project developed as a young researcher at the Universidad Pedagógica y Tecnológica de Colombia and belongs to the research group ELEX of the School of Languages. The purpose was to design, implement, and analyze ten workshops with the intention of strengthening the communicative competence of learners of Spanish as a foreign language (ELE) through descriptive texts. Subsequently, based on the analysis of information, a primer was designed. Methodology: an Action Research methodology was chosen. The approach was mixed as it included both qualitative and quantitative methods. For the application and analysis of the results and the subsequent publication of the primer, four ELE foreign learners attending the Universidad Pedagógica y Tecnológica de Colombia (UPTC) participated in the study. Results: descriptive texts served as a strategy and tool for strengthening the communicative competence of ELE and consolidating the skills of interpretation, reasoning, proposition and analysis, and learning of new vocabulary. Conclusion: Through this research, it was found that ELE students express their ideals, beliefs, and stories objectively and subjectively. Furthermore, the pedagogical proposal focused on playful activities, exercises, and workshops where they were able to read, analyze, criticize, and understand different types of descriptive texts in an effective and pleasant way. Based on the implementation of workshops and their analysis, the primer was designed to strengthen the communicative competence of foreign students.
\end{abstract}

Keywords: communicative competence, ELE (Spanish as a foreign language), ELE teaching, descriptive text.

\section{O texto descritivo para fortalecer a competência comunicativa do espanhol como língua estrangeira}

\begin{abstract}
Resumo
Introdução: este artigo de investigação é produto do projeto desenvolvido como jovem pesquisadora da Universidade Pedagógica e Tecnológica da Colômbia e pertence ao grupo de investigação ELEX da Escola de Línguas. O escopo foi desenhar, aplicar e analisar dez oficinas com o intuito de fortalecer a competência comunicativa dos aprendizes de espanhol como língua estrangeira (ELE), através do texto descritivo. Em seguida, baseado na análise da informação, foi desenhada a caderneta. Metodologia: selecionou-se como metodologia a Investigação - Ação. O enfoque foi misto, já que incluiu tanto o qualitativo quanto o quantitativo. Para a aplicação e para a análise dos resultados e a publicação posterior da caderneta, houve a participação de quatro estrangeiros aprendizes de ELE que visitam a Universidade Pedagógica e Tecnológica da Colômbia (UPTC). Resultados: os textos descritivos serviram como estratégia e ferramenta para o fortalecimento da competência comunicativa do ELE e o reforço das habilidades na interpretação, argumentação, proposição e análise, e o aprendizado de novo léxico. Conclusão: mediante esta investigação, confirmou-se que os estudantes de ELE expressam de objetiva e subjetivamente seus ideais, crenças e histórias. Igualmente, a proposta pedagógica esteve focada em atividades, exercícios e oficinas lúdicas nos quais foram capazes de ler, analisar, criticar e compreender de maneira eficaz e agradável os diferentes tipos de textos descritivos. A partir da aplicação das oficinas e sua análise, foi desenhada a caderneta para fortalecer a competência comunicativa dos estudantes estrangeiros.
\end{abstract}

Palavras-chave: competência comunicativa, ELE (espanhol língua estrangeira), ensino de ELE, texto descritivo. 


\section{Introducción}

Actualmente existe poco material dirigido a los estudiantes de ELE en nivel intermedio y avanzado. Además, los estudiantes extranjeros presentan falencias en los procesos de lectura y escritura, lo cual afecta su competencia comunicativa. Así mismo, es necesario saber que los aprendientes de español como lengua extranjera necesitan estar motivados antes, durante y después del proceso de lectura y escritura de diferentes textos, a fin de fortalecer su competencia comunicativa. Por estas razones, se decidió diseñar y presentar diez talleres que tuvieran como propósito contribuir específicamente en el mejoramiento de la competencia comunicativa en ELE a través de los textos descriptivos. Por lo tanto, con base en el análisis de la información, se diseñó una cartilla que se fundamenta en los textos descriptivos.

Es de conocimiento común que muchos extranjeros que llegan a Colombia o a cualquier país hispanohablante necesitan conocer e interactuar con la cultura de ese lugar. De esta forma, los talleres y las actividades fueron elementos principales para que los extranjeros se sumergieran con la cultura colombiana y tunjana, de manera que fortalecieran su competencia comunicativa en ELE.

Un estudiante de español como lengua extranjera debe saber actuar lingüísticamente en contextos académicos y sociales. En estos espacios, los extranjeros necesitan transmitir sensaciones, emociones y sentimientos en el contexto de cualquier situación comunicativa. Asimismo, se buscó que al fortalecer la competencia comunicativa, los extranjeros estuvieran en capacidad de ser más críticos y reflexivos.

\section{Fundamentación teórica}

En relación con la fundamentación teórica, se consideró oportuno reconocer los aportes de algunos autores quienes sustentan temas referentes al Marco Común Europeo de Referencia para las Lenguas (MCERL); la adquisición, aprendizaje y enseñanza de ELE, su competencia comunicativa y competencia pragmática; así como la cultura e interculturalidad, el taller, la descripción y el texto descriptivo (pasos para realizar una descripción, tipos de descripción y clases de descripción). Todos estos temas sirvieron como soporte para el desarrollo de esta investigación.

\section{Marco Común Europeo de Referencia para las Lenguas (MCERL)}

Con el fin de identificar y evaluar el nivel de dominio de cualquier lengua extranjera en el que el extranjero se encuentra, es necesario recurrir a los parámetros planteados por el Consejo de Europa. De esta manera, se debe entender que este organismo, "define, asimismo, niveles de dominio de la lengua que permiten comprobar el progreso de los alumnos en cada fase del aprendizaje y a lo largo de su vida" (Consejo de Europa 1). En este sentido, esta investigación tuvo en cuenta que los aprendientes de ELE estuvieran entre un nivel intermedio (B2) y avanzado (C1 y C2) de español.

\section{Aprendizaje y enseñanza de ELE}

El docente de ELE debe tener la capacidad de entender y comprender los diferentes elementos que rodean el aprendizaje y la enseñanza de una lengua extranjera. Los seres humanos se ven en la necesidad de aprender diferentes lenguas con fines académicos, comerciales y laborales, entre otros. Por lo tanto, en relación con el aprendizaje de ELE, Da Silva y Signoret aseveran: "Las lenguas extranjeras (LE) son aprendidas de manera formal por los niños y los adultos en las clases de lenguas" (51). De esta manera, el aprendizaje de una lengua extranjera debe ser un proceso consciente en el propósito de comprender y entender lo aprendido. Asimismo, Da Silva y Signoret señalan que el aprendizaje "consiste en asimilar conocimientos que se utilizarán en un futuro, en asimilar conocimientos que cambiarán los conocimientos previos, en asimilar y cambiar habilidades" (55). No obstante, todas las actividades que se realizan diariamente son aprendidas (hablar, leer, escribir, escuchar, saludar, agradecer, manejar, caminar, comer, entre otras). Por consiguiente, el aprendiente de ELE debe estar en capacidad de aprender todo lo relacionado con la lengua que esté estudiando, enfocado en fortalecer la competencia comunicativa y la competencia cultural.

Durante el proceso de enseñanza de alguna lengua extranjera se debe tener en cuenta que el estudiante extranjero debe estar motivado por el docente de ELE, a fin de que el aprendizaje sea efectivo y productivo. De la misma manera, los aprendientes de ELE, al adquirir los saberes y los conocimientos sobre la lengua española, tienen la posibilidad de aplicarlos en diversos contextos (dentro y fuera del aula de clase), tales como la casa, la calle, el centro comercial, 
etc. Esto en razón a que en estos contextos ellos tienen la posibilidad de interactuar con diferentes personas, conocer más sobre la cultura colombiana y aprender expresiones y vocabulario nuevo.

Los docentes de español como lengua extranjera deben diseñar e inventar estrategias creativas e innovadoras para la enseñanza de ELE. Así, parafraseando a Espejo, Flóres y Zambrano (68), la mayoría de extranjeros estudian y se interesan por aprender español con fines académicos, laborales, turísticos y comerciales, entre otros. De la misma manera, estos autores afirman que diferentes extranjeros llegan a Colombia con la intención de aprender a hablar español (70). Pero además de esto, tienen la posibilidad de conocer la diversidad cultural del país (la gastronomía, la música, los lugares turísticos, la literatura, etc).

En Colombia, los docentes de ELE se interesan por la creación de material y textos didácticos para la enseñanza del español como lengua extranjera. Específicamente, en la Universidad Pedagógica y Tecnológica de Colombia, el grupo de investigación ELEX propende hacia el diseño y la creación de diferentes tipos de textos para la enseñanza de ELE, en conformidad con el contexto social colombiano. Actualmente se encuentra publicado el nivel básico y el nivel intermedio de español con actividades y ejercicios prácticos y lúdicos. En este momento, en imprenta se encuentra el nivel avanzado de español Comunicarse en Español: la mejor opción. En esta investigación, los talleres que incluyeron actividades y ejercicios lúdicos buscaron el fortalecimiento de la competencia comunicativa en ELE. De la misma manera, los aprendientes de ELE tuvieron la oportunidad de aprender léxico y expresiones nuevas provenientes de los textos descriptivos.

\section{La competencia comunicativa en ELE}

El componente comunicativo en ELE es primordial dentro del contexto de enseñanza y aprendizaje del español como lengua extranjera. En todos los ámbitos de interacción comunicativa, los aprendientes pueden lograr trasmitir emociones, sensaciones y sentimientos sobre un tema específico o coloquial. Asimismo, la competencia comunicativa ofrece la posibilidad de que los estudiantes sean cada vez más imaginativos, críticos, reflexivos y creativos. Por consiguiente, se pretendió vincular habilidades lingüísticas tales como el apropiado uso del lenguaje, el manejo de las reglas ortográficas, el desarrollo de la imaginación y la creatividad, entre otras, con el contexto sociocultural colombiano y tunjano. En este sentido, Niño considera la competencia comunicativa:

Como un saber comunicarse en un campo del conocimiento y un saber aplicarlo, saberes que comprenden conocimientos, habilidades, actitudes y valores (precondiciones, criterios, usos, reglas, normas, etcétera) que habilitan para realizar actos comunicativos eficientes, en un contexto determinado, según necesidades y propósitos. (25)

Para Lyons, citado por Colmenares, "la competencia comunicativa son los conocimientos y aptitudes que necesita una persona para utilizar todos los sistemas de signos que tiene a su disposición como miembro de una determinada comunidad sociocultural" (248). Finalmente, la competencia comunicativa es la suma de catorce competencias más, así como de factores relacionados con el contexto y todo aquello que rodea a la comunicación.

La competencia comunicativa busca fortalecer y mejorar el uso correcto y apropiado de la lengua. Igualmente, conlleva el desarrollo de algunas competencias ciudadanas tales como saber escuchar y valorar lo expresado por los demás. En suma, lo que se pretendió con el desarrollo de esta investigación fue fortalecer la competencia comunicativa de los aprendientes de ELE a través de los textos descriptivos.

\section{La competencia pragmática en ELE}

La pragmática es una disciplina que les permite a los interlocutores (hablantes) interpretar los enunciados, y así lograr una apropiada comunicación. Por consiguiente, Escandell afirma que la pragmática es:

El estudio de los principios que regulan el uso del lenguaje en la comunicación, es decir, las condiciones que determinan tanto el empleo de un enunciado concreto por parte de un hablante concreto en una situación comunicativa concreta, como su interpretación por parte del destinatario. (13-14)

Además, en palabras de Bertucelli, esta disciplina es considerada como "la ciencia de las relaciones entre los signos y sus intérpretes teniendo en cuenta que debe haber un interlocutor que entienda lo que se quiere decir" (33).

Así, en los contextos de ELE, es primordial destacar la relación que existe entre la pragmática y todos 
los elementos necesarios para que los interlocutores entiendan y comprendan sus intenciones comunicativas de acuerdo con el contexto, su intención comunicativa y los elementos paralingüísticos (sonidos, silencios, voz, llanto, entre otros), así como los extralingüísticos (gestos, maneras de actuar y la distancia entre los hablantes).

\section{Cultura e interculturalidad}

En la enseñanza y en el aprendizaje de lenguas extranjeras se deben tener presentes los elementos culturales para que pueda haber interculturalidad. Por lo tanto, es fundamental tener presente que la cultura es todo lo que está a nuestro alrededor: creencias, tradiciones y costumbres, entre otros. De acuerdo con Abello, De Zubiría y Sánchez:

La cultura en general y la producción cultural en particular son un invento, producto de una fuerza activa que produce un acto creador, susceptible de ser inventado no por fuera del tiempo y del espacio, sino dentro de un conjunto de condiciones que facilitan su aparición de manera específica, fuerza, pues que genere determinadas posibilidades. (31)

De esta manera, además de conocer el concepto de cultura, se debe entender y comprender el concepto de interculturalidad. Así, Abello, De Zubiría y Sánchez postulan también lo siguiente:

La noción de lo intercultural parte del hecho de que las culturas no se encuentran aisladas ni se producen por generación espontánea. Más bien, en su diario acontecer, tienden a abarcar espacios que las conducen a entrar en relaciones con otras culturas. $Y$ esas relaciones que se establecen entre las culturas es lo que se denomina interculturalidad. (206)

\section{Añaden:}

La interculturalidad puede darse de distintos modos, pero predominantemente de tres formas. La primera, cuando al entrar en contacto con otras culturas tiende a hacerlas desaparecer, estableciendo relaciones de dominación y no reconocimiento. La segunda, sepresentacuandoal contactarse doso más culturas, se parte del reconocimiento del contexto y de particularidades de la o las otras culturas. Se establece así una relación de diálogo y respeto que genera modificaciones significativas en los escenarios simbólicos de las culturas que han entrado en interacción. La tercera, en el caso de que se establezcan relaciones de contacto entre dos o más culturas, incluso existiendo relaciones de reconocimiento, las culturas, interactuantes no resultan afectadas o modificadas por el encuentro o el diálogo. En consecuencia, podemos sostener que no toda relación de tipo intercultural es necesariamente multicultural, pero toda relación multicultural es necesariamente intercultural. La primera y la tercera relaciones son relaciones interculturales, pero no son de carácter multicultural; mientras la segunda, es tanto intercultural como multicultural. (206-207)

Con la intención de entrar más a fondo en los propósitos de esta investigación, es ineludible considerar el planteamiento de Sánchez. Para llegar a desarrollar esa perspectiva intercultural, el hablante o estudiante de ELE debe poseer una serie de destrezas y habilidades, también interculturales:

- La capacidad de relacionar entre sí la cultura de origen y la cultura extranjera.

- La sensibilidad cultural y la capacidad de identificar y utilizar una variedad de estrategias para establecer contacto con otras personas de otras culturas.

- La capacidad de cumplir el papel de intermediario cultural entre la cultura propia y la cultura extranjera, y de abordar con eficacia los malentendidos interculturales y las situaciones conflictivas. (2)

\section{El taller}

Una de las herramientas elementales dentro del proceso de enseñanza y aprendizaje es el uso del taller. En pedagogía, el taller es concebido como una forma de enseñar, aprender y comprender diferentes temáticas. En conformidad con lo referido por Ander (10), el taller es "una forma de enseñar y, sobre todo de aprender, mediante la realización de 'algo', que se lleva a cabo conjuntamente. Es un aprender haciendo en grupo". Asimismo, con el taller se pretende integrar la teoría con la práctica de una manera dinámica y activa. De acuerdo con De Vincenzi:

El aula taller constituye un escenario para aprender haciendo, a partir de la negociación de significados entre el docente y los alumnos sobre los criterios en la elaboración del programa de trabajo y sobre las 
expectativas de los resultados esperados. Supone un espacio de trabajo cooperativo en torno a descripciones, explicaciones, críticas y orientaciones sobre el abordaje del proceso de producción propuesto por cada estudiante. (42)

Durante el desarrollo de un taller el aprendizaje debe ser dinámico, individual o grupal, con miras a favorecer la ayuda mutua, el contraste y el estímulo. Los talleres buscan desde una perspectiva didáctica trabajar los procesos de aprendizaje, en este caso la lectura. En el desarrollo de esta investigación se optó por utilizar talleres dinámicos a fin de fortalecer la competencia comunicativa de los aprendientes de ELE. En definitiva, se debe concebir el taller como un instrumento elemental, ya que le permite al docente de español como una lengua extranjera diseñar y aplicar sus actividades de una manera creativa y lúdica, con el fin de lograr motivar a sus estudiantes durante el aprendizaje y la enseñanza de esta lengua.

\section{La descripción}

Describir es explicar — de forma detallada - cómo son las personas, los animales, los lugares o los objetos. De acuerdo con Parra (124), "los textos de estructura descriptiva son aquellos cuya intención comunicativa es representar lingüísticamente la imagen de un objeto de la realidad (exterior e interior, natural o social) o de un proceso que se lleva a cabo". Describir es pintar con palabras la imagen, el mundo real o imaginario que se quiere representar.

En la vida diaria y académica, la descripción es uno de los tipos de discurso más utilizados. De acuerdo con Pérez:

En la retórica clásica, la descripción es una figura de las llamadas pintorescas, por cuanto se dirige a la imaginación, presentando y dándole realce a los objetos. 'Describir' - decía Fray Luis de Granada- es exponer lo que sucede, o ha sucedido, no sumaria y ligeramente, sino por extenso y con todos sus colores, de modo que poniéndolo delante de los ojos del que lo oye o lo lee, como que lo saca fuera de sí y lo lleva al teatro. (125)

Niño, por su parte, plantea que "describir es representar por medio del lenguaje la imagen de objetos -materiales e inmateriales-, personas y demás seres vivos, paisajes, situaciones y los diversos aspectos de la realidad, para señalar sus dimensiones, formas, relaciones, perspectivas, cualidades y características" (219-220). Igualmente, Vargas asegura: "En la comunicación diaria hacemos uso frecuente de la descripción. Organizamos las palabras con el propósito de presentar o de evocar la presencia de una persona o una cosa” (152).

Es evidente que los anteriores autores conciben la descripción de la misma manera. En síntesis, describir es explicar, relatar o recrear con palabras lo que se observa o se siente. Con la descripción es posible dar detalles sobre las personas, los animales, los lugares, los paisajes, los objetos, las emociones, en consonancia con nuestra intención. Los elementos de una descripción son la precisión, la claridad y la coherencia.

\section{El texto descriptivo}

Un texto es un tejido de ideas coherentes. En este sentido, Horcas afirma que un texto "es la unidad superior de comunicación que contiene y se apoya en tres características: coherencia, cohesión y adecuación" (1). Niño, por su parte, propone que "el objetivo del texto descriptivo es suscitar en la imaginación del lector una impresión similar a la impresión sensible que pudieran provocar las cosas descritas" (219-220). Así, el eje central de esta investigación ha sido utilizar el texto descriptivo con el fin de fortalecer la competencia comunicativa de los aprendientes de ELE. Cervera et al. postulan lo siguiente:

Los textos descriptivos presentan con claridad y rigor los rasgos característicos de personas, animales, objetos, lugares, fenómenos o situaciones. Realizar una buena descripción exige: observar o pensar atentamente sobre lo que se va a describir, seleccionar los rasgos más característicos de esa realidad (forma, elementos constituyentes, color, tamaño, gusto, olor...), ordenar los elementos seleccionados (de arriba abajo, de izquierda a derecha, de delante a atrás...) y redactar la descripción teniendo en cuenta el fin perseguido: objetividad/subjetividad, expresividad. (61)

Además, Cervera et al. aseguran que el texto descriptivo:

Recurre a los sentidos para transmitir las impresiones y las sensaciones de la realidad percibida. A través de la descripción reflejamos los colores, las formas, los tamaños, los ruidos, los movimientos y las emociones. Con la vista observamos el objeto y los situamos 
en el espacio; con el oído captamos los sonidos, las tonalidades de voz, los ruidos, la música; con el olfato, los olores; con el tacto percibimos la textura, la forma y la temperatura; con el gusto los sabores. (61)

En esta investigación se recurrió al texto descriptivo para que el aprendiente de ELE sea capaz de describir a través de sus sentidos y logre ser competente comunicativamente.

\section{Pasos para realizar una descripción}

De acuerdo con Vargas, los principios básicos de la descripción son:

1. Observar atentamente el objeto de la descripción, y seleccionar las características o peculiaridades que lo identifican y diferencian de otros objetos de su misma clase. Por ejemplo, si se describe un perro, puede resultar expresivo nombrar una mancha en el lomo, una mirada dócil u otras características que lo hacen diferente de los demás perros.

2. Ordenar los materiales obtenidos, siguiendo criterios como: de lo particular a lo general, de lo más expresivo a lo menos expresivo.

3. Redactar con exactitud y expresividad, buscando influir sobre quien nos escucha o no lee. (153)

Las descripciones son utilizadas en la mayoría de los textos que se escriben. La intención es brindar detalles y hacer que quien lee los textos descriptivos pueda imaginar de lo que se está hablando, bien sean objetos, animales o personas. Además, se hace uso de los adjetivos y elementos figurativos para dar detalles sobre la apariencia de lo que se desea describir.

\section{Tipos de descripción}

Parafraseando a Parra (124-125), el texto descriptivo se caracteriza por ser objetivo o científico-técnico, y subjetivo o literario: a) objetivo, ya que describe las cosas como aparecen en la realidad, dando a conocer sus partes, su funcionamiento y su finalidad (para qué sirve). La persona quien describe no manifiesta sus sentimientos o emociones. Se utiliza, por ejemplo, en los documentos científicos. Ejemplo: "El río Magdalena es el más grande y caudaloso de Colombia. Está rodeado de mucha vegetación. Suele haber pájaros e insectos". b) Subjetivo, pues se expresa la realidad interior y exterior de lo que se desea describir, se utiliza un lenguaje embellecido con epítetos, metáforas, comparaciones y otras figuras literarias. En la descripción subjetiva se reflejan los sentimientos y las emociones. Se suele utilizar en descripciones literarias. Ejemplo: "Ella era tan hermosa como una flor. Sus ojos eran grandes luceros que invadían mi ser".

\section{Clases de descripción}

De acuerdo con Ariza (2), la descripción incluye las siguientes clases:

- Topografía. Descripción de un lugar o paisaje, un espacio físico real o imaginario.

- Cronografía. Descripción de una época histórica, un tiempo o momento determinado.

- Prosopografía. Descripción de los rasgos físicos de una persona o de un animal. Se centra en su figura corporal y la ropa.

- Etopeya. Descripción de las costumbres, las virtudes, los talentos, los defectos y las cualidades morales o psicológicas de las personas.

- Retrato. Es la suma de la prosopografía y la etopeya. Incluye cualidades físicas, morales e intelectuales.

- Autorretrato. El autor se describe a sí mismo.

- Paralelismo. Es la descripción consecutiva o mezclada a fin de establecer una comparación y construir semejanzas y diferencias.

- Caricatura. Deforma la descripción con una intención irónica y humorística.

En este sentido, el papel protagónico en la interrelación entre cultura, formas lingüísticas y aprendizaje de ele lo tienen los textos descriptivos. En fin, se procuró incluir los anteriores tipos de texto descriptivo puesto que los resultados de este estudio se encontraban relacionados, sobre todo, con la realidad que acompaña al extranjero durante su visita a Colombia y a Tunja.

\section{Metodología}

De acuerdo con los objetivos planteados, desde la teoría de la metodología de la investigación este estudio fue una investigación-acción. Esto en razón a que se aplicaron diez talleres a los aprendientes del español como lengua extranjera, los cuales fueron analizados y modificados con base en la primera y la segunda aplicación. Posteriormente, a partir del 
análisis de la información se diseño la cartilla final. De esta manera, en palabras de Bausela, la investigación-acción es:

Una forma de entender la enseñanza, no sólo de investigar sobre ella. La investigación-acción supone entender la enseñanza como un proceso de investigación, un proceso de continua búsqueda. Conlleva entender el oficio docente, integrando la reflexión y el trabajo intelectual en el análisis de las experiencias que se realizan, como un elemento esencial de lo que constituye la propia actividad educativa. Los problemas guían la acción, pero lo fundamental en la investigación-acción es la exploración reflexiva que el profesional hace de su práctica, no tanto por su contribución a la resolución de problemas, como por su capacidad para que cada profesional reflexione sobre su propia práctica, la planifique y sea capaz de introducir mejoras progresivas. En general, la investigación-acción cooperativa constituye una vía de reflexiones sistemáticas sobre la práctica con el fin de optimizar los procesos de enseñanza-aprendizaje. (1)

El enfoque de esta indagación es mixto, ya que incluye tanto el cualitativo como el cuantitativo. El primero Castillo, Chaparro y Jaimes lo conciben como "la interpretación de la realidad desde el punto de vista de los sujetos objeto de estudio" (39). Asimismo, estos autores afirman que la investigación cualitativa "tampoco puede verse como la exclusión de lo cuantitativo, ya que busca la comprensión de la realidad para interpretarla y reconstruirla de una manera objetiva y confiable" (41).

El método fue inductivo ya que para la aplicación y el análisis de los resultados y la publicación posterior de la cartilla, se contó con la participación de cuatro extranjeros que visitan la Universidad Pedagógica y Tecnológica de Colombia y la ciudad de Tunja. De esta manera, en palabras de Bernal Torres, el método inductivo:

Utiliza el razonamiento para obtener conclusiones que parten de hechos particulares aceptados como válido, para llegar a conclusiones, cuya aplicación sea de carácter general. El método se inicia con un estudio individual de los hechos y se formulan conclusiones universales que se postulan como leyes, principios o fundamentos de una teoría. (56)

La muestra poblacional se constituyó con cuatro aprendientes de ELE. La técnica fue la observación directa. Esta técnica permitió observar y analizar la problemática, las características del grupo objeto estudio y el contexto en el que se encuentran los aprendientes de español como lengua extranjera. Asimismo, durante el proceso investigativo se utilizó esta técnica a fin de modificar los talleres propuestos de acuerdo con el análisis de la información y las necesidades de los aprendientes de español como lengua extranjera.

La metodología de la investigación se fundamentó en las siguientes actividades. Primero se realizó el marco referencial, el cual incluyó los antecedentes y el marco teórico que dispuso las teorías necesarias para el desarrollo de esta investigación. Luego, se seleccionaron los textos descriptivos necesarios en el diseño de los talleres, para lo cual se tuvieron en cuenta las dos características de la descripción (objetiva y subjetiva), así como las diferentes clases de descripción (topografía, cronografía, prosopografía, etopeya, retrato, autorretrato, paralelismo y caricatura). En un tercer momento se llevó a cabo la primera aplicación de los cinco primeros talleres a los cuatro aprendientes de ELE. Posteriormente, se analizaron los resultados provenientes de la primera aplicación de los cinco talleres a los estudiantes de ELE, con el objetivo de replantear los ejercicios y las actividades propuestas. Luego, se realizó la segunda aplicación de los últimos cinco talleres con base en los resultados de los cinco primeros talleres aplicados. Una vez hecho lo anterior, se realizó el análisis de la segunda aplicación con base en los resultados provenientes de los segundos talleres aplicados. Finalmente, se diseñó la cartilla final de acuerdo con el análisis proveniente de la aplicación de los diez talleres.

\section{Resultados}

Es importante aclarar que antes de aplicar los primeros cinco talleres, la investigadora dictó una clase de español a cada aprendiente de ELE con el fin de socializar la temática sobre el texto descriptivo, sus propósitos, sus características y las clases de descripción. Los diez talleres se diseñaron en conformidad con las dos características (objetiva y subjetiva) y las clases de textos descriptivos (topografía, cronografía, prosopografía, etopeya, retrato, autorretrato, paralelismo y caricatura). Los talleres incluyeron preguntas e imágenes relacionadas con el contexto colombiano y boyacense. En este apartado se da cumplimiento al primer objetivo específico.

Durante la clase de español sobre el texto descriptivo, los aprendientes de ELE tuvieron la oportunidad 
de repasar y reforzar sus conocimientos sobre la definición, los propósitos, las características y las clases de descripción. Los cuatro extranjeros afirmaron tener un conocimiento básico sobre el texto descriptivo. Por lo tanto, ellos aprendieron y reforzaron todo lo relacionado con esta clase de textos. De la misma manera, los aprendientes de ELE aprendieron léxico nuevo proveniente de la teoría estudiada.

A continuación, se describen los resultados obtenidos de la primera aplicación de los cinco talleres. En la primera aplicación, el alemán 1 afirmó de forma oral que le gustó la mezcla de imágenes y textos cortos diseñada para que él pudiera comprender y responder adecuadamente las preguntas. En relación con el taller $n .^{\circ} 1$, aunque fue detallista, objetivo y crítico en las respuestas dadas, le faltó profundizar y argumentar mejor las dos últimas preguntas del taller. Él aseveró que las imágenes del taller $n{ }^{\circ}$ 2 fueron interesantes y aprendió más sobre la cultura colombiana. En el segundo taller, sus respuestas fueron coherentes y específicas, pero se percibió una debilidad a la hora de intentar argumentar las respuestas del segundo punto. En el tercer taller, el alemán fue crítico y reflexivo. En el taller $n .^{\circ} 4$, las respuestas del aprendiente de ELE fueron objetivas y críticas. Asimismo, en el segundo punto se evidenció la interculturalidad porque aseguró que su cantante favorita es Shakira. De esta manera, se puede concluir que sí es posible lograr que la interculturalidad favorezca el mejoramiento del español como lengua extranjera. En el quinto taller le faltó profundizar mejor la descripción del primer punto. En general, las respuestas dadas por este aprendiente de ELE fueron analíticas y reflexivas, sin embargo, le faltó profundizar y argumentar mejor algunas de sus respuestas.

En el taller $n .^{\circ} 1$, si bien la jamaiquina 1 fue crítica en sus respuestas, le faltó profundizar y explicar mejor las respuestas dadas en todo el taller. Las respuestas del taller $n .^{\circ} 2$ fueron coherentes, pero se percibió una debilidad a la hora de intentar argumentarlas. En el primer y el último punto del tercer taller le faltó ser más detallista y descriptiva con su respuesta. En el cuarto taller, si bien respondió las preguntas, le faltó completar, profundizar y describir mejor la información. En el quinto taller fue muy específica y detallista. En general, aunque ella fue objetiva y utilizó diferentes elementos descriptivos, le faltó más argumentación en la mayoría de las respuestas dadas.

La francesa 1, en la primera parte del taller fue objetiva y detallista en la descripción del reloj. En relación con el segundo punto, fue específica, objetiva y detallada en su descripción. En la tercera parte del taller, en la parte $\mathrm{B}$, aunque explicó la respuesta, le faltó profundizar. En la primera parte del segundo taller fue muy objetiva y detallista en la descripción del paisaje de Cartagena. En el segundo punto, en la parte A le faltó explicar mejor la respuesta. En la parte в fue específica y detallista. En la última parte del taller fue muy subjetiva y utilizó diversidad de adjetivos. En el tercero y en el cuarto taller, la aprendiente de ELE fue específica y coherente en las respuestas dadas. Además, se vio su capacidad creativa al momento de escribir. En el quinto taller fue objetiva, subjetiva, detallista y creativa. En general, ella fue creativa en sus respuestas. Sin embargo, en algunas le faltó profundizar y explicarlas mejor.

A la estadounidense 1, en el primer taller, le faltó profundizar y explicar claramente sus respuestas. En el taller $\mathrm{n}^{\circ} 2$ y 3 , ella afirmó que aprendió vocabulario y expresiones desconocidas provenientes de los textos descriptivos. Sin embargo, le faltaron más argumentos en las repuestas dadas en el segundo taller. En el taller $n .^{\circ} 3$, la aprendiente de ELE argumentó y fue coherente en sus respuestas. En el taller $n .^{\circ} 4$, sus respuestas fueron coherentes y argumentadas. En el quinto taller, ella fue subjetiva y utilizó diferentes epítetos. En general, las respuestas dadas por esta aprendiente de ELE fueron correctas desde el punto de vista gramatical y permiten reconocer un nivel de lectura analítico; sin embargo, se mostró debilidad a la hora de argumentar mejor las respuestas dadas.

En síntesis, los cuatro extranjeros aseguraron que las actividades y los ejercicios de los cinco primeros talleres fueron agradables y dinámicos. Además, que gracias a estos tuvieron la oportunidad de aprender vocabulario y expresiones nuevas, así como conocer más sobre la cultura colombiana y boyacense.

Al analizar cada uno de los cinco primeros talleres aplicados, se replantearon las actividades y los ejercicios de los cinco últimos talleres. De esta manera, estos se aplicaron con el fin de que los extranjeros leyeran, analizaran y contestaran analíticamente las preguntas. Por consiguiente, se pretendió que los aprendientes desarrollaran y fortalecieran su capacidad interpretativa, analítica y propositiva a fin de alcanzar competencias comunicativas.

El alemán 1, en el taller $n .^{\circ} 6$ describió de manera objetiva y concreta el computador portátil y el celular. Sin embargo, le faltó claridad en la escritura. En la última parte del taller, él argumentó y fue crítico en su respuesta. En el séptimo taller, las respuestas 
de este aprendiente de ELE fueron coherentes, específicas y argumentadas. Además, él afirmó que ha ido varias veces a Villa de Leyva, y le gustó porque es un lugar cálido y muy turístico. En el octavo taller, utilizó diversidad de adjetivos, argumentó y explicó de manera coherente sus respuestas. En el último punto se comprobó su capacidad subjetiva y reflexiva. En el noveno taller, es posible afirmar que fue capaz de expresar sus sensaciones y sus emociones. En el décimo fue objetivo, crítico, reflexivo y argumentativo en las respuestas escritas. En general, con base en sus respuestas se puede afirmar que él fue capaz de expresar sus sensaciones, sus emociones y sus gustos, así como se observa un buen nivel argumentativo y analítico. Además, en este taller se vio la interculturalidad.

A la jamaiquina 1, en el taller $n .^{\circ} 6$, tanto en el primero como en el segundo punto, le faltó especificar y describir mejor los objetos. En la última parte del taller, aunque escribió la descripción, le faltó profundizar mejor su respuesta. En la primera parte del séptimo taller le faltó describir mejor el lugar. De forma oral, ella afirmó que ha ido dos veces a Villa de Leyva y le encantó el lugar porque tiene un excelente clima. En el segundo punto, le faltó argumentar mejor la respuesta dada. En el cuarto y quinto punto, argumentó y explicó cada una de las respuestas dadas. En el octavo taller, le faltó ser más específica y detallista en el primer punto. Los demás fueron argumentados, subjetivos y autocríticos. En el primer punto del taller n. ${ }^{\circ}$, le faltó completar el retrato de Juanes ya que fue muy breve. Ella afirmó que él es famoso y muy guapo. En la segunda y tercera parte del taller, su descripción fue objetiva, crítica, detallista, subjetiva, utilizó diferentes epítetos y figuras retóricas. En el décimo taller, ella fue muy objetiva, específica y detallista en las respuestas escritas. En síntesis, es posible afirmar que la aprendiente de ELE es capaz de expresar sus emociones y sus gustos. Además, se evidenció un buen nivel argumentativo y analítico. Asimismo, se pudo concluir que sí es posible lograr que la interculturalidad favorezca el mejoramiento de la competencia comunicativa en ELE.

La francesa 1, en el taller $n^{\circ} .6$, proporcionó respuestas objetivas, detallistas, críticas y analíticas. En el primer punto del séptimo taller, ella describió de manera objetiva y detallista la plaza central de Villa de Leyva. En su texto, utilizó diversidad de elementos, tales como adjetivos, sustantivos y figuras literarias. En los demás puntos fue coherente y argumentó las respuestas dadas. En la última parte del taller se mostró subjetividad y espontaneidad al escribir una breve cronografía de una etapa de su niñez. En la primera parte del octavo taller, ella fue objetiva y detallista en la prosopografía de James Rodríguez. En el segundo punto, explicó su respuesta adecuadamente afirmando que el texto es una prosopografía subjetiva. En la tercera parte del taller se evidencia subjetividad y el uso de epítetos. En la última parte se evidencia su capacidad autocrítica y autoreflexiva. En la primera parte del noveno taller, la aprendiente de ELE fue objetiva, subjetiva y argumentativa en el retrato del cantante colombiano Juanes. En el segundo punto su descripción fue objetiva y detallista. En el tercer punto se evidencia su capacidad objetiva y crítica. En la primera parte del taller $\mathrm{n}^{\circ} .10$, fue objetiva, analítica y detallista. En la segunda parte, fue crítica y argumentó de manera coherente su posición. En general, sus respuestas fueron más creativas, argumentadas y analíticas.

La estadounidense 1, en la primera parte del sexto taller, describió de manera objetiva, subjetiva y concreta el computador portátil. Sin embargo, hubo algunos errores de sintaxis en palabras y frases. En la segunda parte, describió el celular de manera objetiva y tuvo en cuenta para esto la forma, el tamaño, las partes constitutivas y la utilidad. En el tercer y cuarto punto del taller respondió con argumentos. En la primera parte del taller $n^{\circ} .7$, la aprendiente de ELE escribió una topografía objetiva de Villa de Leyva, utilizó diversidad de epítetos para describir el lugar. De forma oral, ella manifestó que le encanta este pueblo porque es cálido y tiene mucha vegetación. En el tercer punto describió el lugar de manera objetiva. En la cuarta parte del taller, le faltó explicar mejor su respuesta. En la última parte escribió una breve cronografía recordando una etapa de su adolescencia. En el octavo taller, la aprendiente de ELE fue objetiva y específica en la prosopografía del deportista colombiano James Rodríguez. Ella afirmó de forma escrita y oral que él es muy guapo. En la segunda parte, le faltó argumentar mejor la respuesta dada. En la tercera parte del taller, utilizó diversidad de adjetivos y elementos figurativos. En el cuarto punto, fue subjetiva, autocrítica y observadora. En el primer punto del noveno taller, la aprendiente de ELE fue objetiva y específica en el retrato del cantante colombiano Juanes. Además, escribió que él es muy guapo. En la segunda parte del taller, escribió el retrato de su actor favorito, describió su forma física y personal. En la tercera y última parte se observan aspectos subjetivos y compara personalidades. En el primer 
punto del décimo taller, la aprendiente de ELE escribió aspectos objetivos y subjetivos. Afirmó que Tunja es más bonita que Bogotá. Para ella, Bogotá es muy estresante. En la segunda parte del taller, fue crítica y analítica. En general, fue subjetiva y utilizó diferentes epítetos para describir los lugares. Asimismo, en ella se muestra un nivel argumentativo considerable. Además, las respuestas dadas por esta aprendiente de ELE fueron coherentes y permiten reconocer un nivel de lectura analítico y crítico.

En síntesis, los cuatro aprendientes de ELE aseveraron que las actividades y los ejercicios de los últimos cinco talleres fueron dinámicos y entretenidos porque tenían imágenes y textos cortos. De esta manera, aprendieron nuevos aspectos sobre la cultura colombiana y tuvieron la oportunidad de expresar sus conocimientos, ideas e impresiones de manera objetiva y subjetiva. Finalmente, los cuatro extranjeros fueron más analíticos, críticos, reflexivos, argumentativos y creativos en sus respuestas logrando fortalecer su competencia comunicativa. Al analizar la información, se replantearon las últimas actividades para el diseño de la cartilla final.

\section{Conclusiones}

Es importante resaltar que por medio de esta investigación se comprobó que los estudiantes aprendientes de ELE expresan de manera objetiva y subjetiva sus ideales, creencias e historias. Los cuatro extranjeros afirmaron que los diez talleres despertaron en ellos el goce por leer, observar, analizar, interpretar y comprender diversos tipos de textos descriptivos, ya que por medio de estos fue más fácil analizar y entender las dos características de la descripción (objetiva y subjetiva), y las diferentes clases de descripción (topografía, cronografía, prosopografía, etopeya, retrato, autorretrato, paralelismo y caricatura). Asimismo, los aprendientes disfrutaron cada uno de los talleres porque estos incluyeron aspectos culturales propios de Colombia y Boyacá.

De igual forma, la propuesta pedagógica se enfocó en actividades, ejercicios y talleres lúdicos en los que los estudiantes aprendientes de ELE pudieron leer, analizar, criticar y comprender de forma fácil y agradable diferentes tipos de textos descriptivos. Las actividades incluyeron el uso de diez textos descriptivos con imágenes, cuyo fin era fortalecer la capacidad argumentativa y analítica de los aprendientes, así como lograr su competencia comunicativa en ELE. Además, los extranjeros tuvieron la oportunidad de conocer y aprender vocabulario desconocido, expresiones nuevas y, en general, aspectos sobre la cultura de Colombia, Boyacá y Tunja.

Como conclusión se detectó que los textos descriptivos sirvieron como estrategia y herramienta para el fortalecimiento de la competencia comunicativa del español como lengua extranjera, ya que los aprendientes de ELE, además de fortalecer habilidades tales como la interpretación, la argumentación, la proposición, la creación y el análisis, incorporaron léxico y nuevas expresiones provenientes de cada uno de los textos descriptivos.

Igualmente, por medio de los diez talleres, los aprendientes de español como lengua extranjera conocieron y entendieron más sobre la cultura colombiana, boyacense y tunjana en la que están inmersos. Cabe resaltar que la mayoría de sus respuestas fueron críticas, analíticas, descriptivas, reflexivas, argumentadas y creativas. Aunque las actividades y los ejercicios de los diez talleres fueron dinámicos para los cuatro extranjeros aprendientes de ELE, algunas preguntas y ejercicios fueron modificados en la cartilla final de acuerdo con las observaciones que ellos hicieron acerca de los diez talleres.

Finalmente, las recomendaciones a los futuros investigadores que deseen trabajar e investigar temas relacionados con el español como lengua extranjera, se enfocan en diseñar y aplicar ejercicios, así como actividades dinámicas y entretenidas que involucren aspectos culturales, sociales y académicos en el fortalecimiento de la competencia comunicativa en ELE. Además, se recomienda usar imágenes y textos cortos para que el aprendizaje sea más dinámico, lúdico $y$ representativo.

\section{Referencias}

Abello, Ignacio, De Zubiría, Sergio y Sánchez, Silvio. Cultura: teorías y gestión. San Juan de Pasto: Ediciones Unariño, 1998. Impreso.

Ander-Egg, Ezequiel. El taller, una alternativa para la renovación pedagógica. Argentina: Libris, 1991. Impreso.

Ariza, Manuel. La descripción: Lengua castellana y literatura. Vol. 2. (s.f.). Web. 20 de noviembre del 2013. <http:// www.mallorcaweb.net/colsantoniab/Ampliaciones/ La\%20descripcion.pdf>.

Bausela, Esperanza. "La docencia a través de la investigación-acción". Revista Iberoamericana de Educación (s.f.). Web. 30 de octubre del 2014. http:// www.rieoei. org/deloslectores/682Bausela.PDF 
Bernal, César. Metodología de la investigación. México: Pearson Educación, 2006. Impreso.

Bertucelli, Marcélla. ¿Qué es pragmática? Barcelona: Paidos Ibérica, 1993. Impreso.

Castillo, Nora, Chaparro, Ramón. y Jaimes, Gladys. Una aproximación a la investigación cualitativa. Tunja: Universidad Pedagógica y Tecnológica de Colombia, 2001. Impreso.

Cervera, Ángel et al. Saber escribir. Bogotá: Aguilar, 2007. Impreso.

Colmenares, Sol. El libro del lenguaje 6 castellano y literatura: Guía de docencia. Bogotá: Voluntad, 2003. Impreso.

Da Silva, Helena y Signoret, Aline. Temas sobre la adquisición de una segunda lengua. México: Trillas, 2005. Impreso.

De Vincenzi, Ariana. "La práctica educativa en el marco del aula taller". Revista de Educación y Desarrollo, 10 (2009): 41-47. Web. 20 de junio del 2014.

Escandell, María Victoria. Introducción a la pragmática. Barcelona: Ariel, 2002. Impreso.

Espejo, María Bernarda, Flórez, María del Pilar y Zambrano, Ivonne. Tendencias de los estudios de español como lengua extranjera (ELE) en Bogotá. Instituto Caro y Cuervo, s.f. Web. 5 de marzo del 2014. <http://www. lenguasdecolombia.gov.co/revista/sites/ lenguasdecolombia.gov.co.revista/files/05_Maria_Bernarda_ otros_0.pdf>.
Horcas, Jóse. “Texto descriptivo". Contribuciones a las Ciencias Sociales (2009). Web. 24 de agosto del 2014 www. eumed.net/rev/cccss/ 03/jmhv6.htm.

Instituto Cervantes. Marco Común Europeo de Referencia para las Lenguas. (s.f.). Web. 14 de abril del 2014. <http://educacio.ua.es/es/secretaria/documentos/ master/niveles-lengua-extranjera.pdf>

Consejo de Europa. Marco Común Europeo de Referencia para las Lenguas: Aprendizaje, Enseñanza y Evaluación. Madrid: Ministerio de Educación, Cultura y Deporte, 2002. Web. 10 de abril del 2014. <http:// www. mineducacion.gov.co/ 1621/articles 237704_archivo_ pdf_marco_europeo.pdf>.

Niño, Víctor. Competencias en la comunicación: hacia las prácticas del discurso. Bogotá: Ecoe ediciones, 2011. Impreso.

Parra, Marina. Cómo se produce el texto escrito: Teoría y práctica. Bogotá: Magisterio, 1996. Impreso.

Pérez, Héctor. Nuevas tendencias de la composición escrita. Bogotá: Magisterio,1999. Impreso.

Sánchez, Marta. “A vueltas con la interculturalidad: hacia una lingüística intercultural para estudiantes alemanes de ELE”. Marco ELE. Revista de didáctica ELE, 7 (2008): 1-13. Web. <http://marcoele.com/descargas/ 7/ sanchez_interculturalidad.pdf $>$.

Vargas, Claudia Español y literatura 7. Educación básica secundaria. Bogotá: Santillana,1999. Impreso. 